\title{
Student's Perception regarding the Effect of Faculty based Assess ment Approaches on their Academic Performance at University Level
}

\author{
* Sadia Mushtaq, Assistant Professor \\ ** Dr. Erum Aslam Khan, Assistant Professor (Corresponding Author) \\ *** Dr. Muhammad Zafar Iqbal, Co-ordinator
}

\begin{abstract}
Instructional and assessment methods are varied and preferred by their teachers at higher-level institutions. A teacher guides their students with detail information and instructions to achieve their educational targets. Students share views regarding their faculty norms and standards that influence the adoption of their study methods. The major focus of this study was to find out the faculty-based differences of learners' views of assessment and its relationship with achievement at the university level. The study was correlational and the survey was conducted to investigate the research problem. All the public sector universities of Punjab were considered as a population of the study and only seven (07) public sector universities were taken as a sample. A questionnaire, students' perception of assessment (Waldrip et al., 2008) was adapted to collect the data from the respondents. Using the mean scores, standard deviation, $t$-test, and regression the collected data were analyzed. The findings of the study showed students have not the same perception about the assessment and the study concluded a significant relationship between students' perception of assessment and academic outcomes. Based on the study results, it was recommended that each faculty should well inform the students about the assessment methods and strategies for their outcomes improvement.
\end{abstract}

Keywords: $\quad$ Students' Perception, Gender, Faculties, Achievement, Assessment, University Level Introduction

Higher education institutions in any country are accountable for their progress, for their influential and valuable responsibility in structuring the societies and promoting their social services, research, training, and education (Omar et al, 2020). Globalization and technological advancement direct the students and make them able to face new challenges. These improve the quality of the educational system and the level of students' outcomes (Alawneh, 2016; Dkhikh et al., 2017).

Assessment is the main aspect of development in the institution of higher education; its authentic and affective role improves the performance of students. The stakeholders of the assessment process need to fulfill their contribution actively to achieve the objective of the assessment. For the progress and development of university students, the autonomous bodies of universities should change the curriculum, assessment methods, and comprehensive accommodations for the new change (AlOtaibi, 2015).

Assessment plays a major role in the achievement of educational objectives. It is a planned activity of skills orientation that enhances the knowledge and brings a change in the behavior of students (Mahasneh, 2020a; Tawarah \& Mahasneh, 2020). Krause (2008) viewed that faculties select the accurate strategy of assessment as it is the only factor that led students to conceptual and contextual deve lopment. Mahasneh (2020b) suggested that in the process of learning, especially at the university level, faculty members must pay attention to the instructional process and solve the learning problems of students (Lenman \& Shemmer, 2012).

Furthermore, there is also a need to pay attention to the application of suitable assessment techniques. The achievement of students' learning can be improved by impartial and carefully planned assessment approaches (Coghill\& Sonuga-Barke, 2012; Mahasneh 2020c). Elliot and Dweck (1988) viewed that students get a high score by adopting skills and mastery techniques (Dweck, 2006). Some

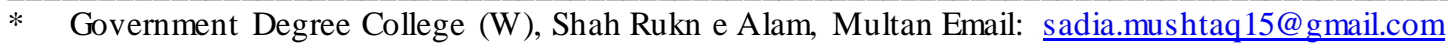

** Department of Education, Bahauddin Zakariya University, Multan, Pakistan

Email: erumkhan63@hotmail.com

*** Admin Branch; Board of Intermediate \& Secondary Education, Multan Email: m.zafariub@gmail.com
} 
students performed well when they are determined to achieve the task for their personal development while some perform better to avoid the negative assessment. These two perceptions of students about assessment and their assessment challenges should be considered before the planning of assessment.

Institutions make a reflective practice to improve the educational goals for students who learn in that organization (Frankford et al., 2000). Students and institutions need are fulfilled by education which not only supports them for the sake of some specific time tasks but also for throughout the life (Teunissen\& Bok, 2013). Institutions and their faculties have their educational system which is more or less different by method and techniques according to the demand and requirements of subject material. Kle in et al., (2017) proposed that although each faculty deliver the instructions to students for their growth orientation, if the purpose of the assessment is just to create a competitive environment, then the learning aspect is neglected (Tabernero\& Wood, 1999). Moreover, instructions about assessment should be clearly explained to the students for the progress of educational outcomes (MacNeil, 2009). Institutional customs and patterns are the main assumptions, values, and standards as expressed by 'what to do, how to do, and who is doing it' (Howe, 2002). Students' active role in the process of institutional assessment strategies helped them in achieving their learning tasks (LaDonna et al., 2017).

The assessment methods (seminars, educational games, web-quests, etc.) used to evaluate the students' learning outcomes determine the traits of its faculties (Galustyan, 2017). It is observed that often faculty members applied different assessment methods without considering the learning outcomes which is not for the sake of students, they just want to cover their course content (Batool, 2018). Thinking skills are not provoked in the assessment process; they are just stuck and fixed with the method of memorization and understanding of the material (krathwole, 2002). The researcher stated that teachers have the knowledge of various methods of assessment and also have the ability to use a variety of assessment methods according to the need of subject material. Faculty members stated that they face obstructions from the management of institutions (Batool, 2018).

Various forms and methods of assessment are used for the evaluation of students' outcomes at the university level. Generally, activity-based approach and contextual approaches are used for educational achievements to improve the students' behavior and enhance the creative abilities of students (Galustyan, 2017).

The study findings of Bliuc et al., (2011) and Platow et al., (2013) showed a relationship between faculties and students' learning methods. Symth et al., (2015) stated that the social group is the main predictor of students' learning process. Students are identified by the ir faculty group and they are influenced by the norms and learning behavior of their group. So, the symth et al, and his colleagues revealed a relationship between students' study process and their faculty group. Considering the above discussion, the researcher conducts this study that students of different faculties have different perceptions regarding assessment and their relationship with academic achievement at the university level. This study may be an attempt to guide the teachers to understand the perceptions of students about assessment.

\section{The Present Study}

The assessment in the higher education system is the most eminent aspect. It is linked with the development of the system as well as linked with student's growth, achievement, and enhancement of their creative abilities (Afaneh, 2011; AL- Kreimeen, 2017). The quality of the higher education system is based on the application of new and modern assessment methods and learners' views. To cope with the rapidly growing society of information technology, higher education must carry out the changes accordingly (Omer et al., 2020).

Tawarah and Mahasneh (2020) viewed that the instructional process should be planned and focused to fulfill the requirements of students' attitudes, behaviors, skills, abilities and make desirable changes in the student's behaviors (Mahasneh, 2020a). Considering the above-cited discussion, this study has tried to attempt the faculty-wise differences of students' perception of assessment and linked with their achievement.

\section{Research Questions}

The main objective of the study was to investigate the faculty-based differences in students' perceptions about assessment. The following questions addressed the research questions:

1. Is there any faculty-based difference in students' perception of assessment? 
2. Is there any relationship between different faculties' students' perception of assessment and their academic achievement?

\section{Research Methodology}

A survey method was applied to evaluate the objectives of the study. The survey design is the most common and easily conducted to the concerning population ( $\mathrm{Li}$ et al., 2021). The general public sector universities (twenty-five) of Punjab province were the population of the study and the sample was selected by using the simple random sampling technique. All the members of the population have equal chances to be selected (Thomas, 2020). The sample of universities and their three faculties was randomly selected. Sample of Students from these faculties was also selected by simple random sampling technique.

After reviewing the literature, a questionnaire which was consisting of two sections adapted regarding the perception of assessment. The first section was about participants' demographic characteristics (semester year, sex, discipline, and CGPA) and the second section contained five different factors that related to participants' perceptions of assessment. A 27-item 5-point Likert scale questionnaire was used. The questionnaire has 5 main factors which include 27 items about students' perception of assessment. These factors were congruence with planned learning constituted 6 items, 4 items of authenticity, 4 items of students' consultation, 7 items for transparency, and 6 items of students' capabilities. The questionnaire was validated and improved with the guidelines and opinions of experts of education departments.

\section{Data Analysis and Results}

The data were analyzed by applying the descriptive (Mean, SD) and the inferential (t-test, regression) statistics. Data were coded and analyzed by using the SPSS (version 23). The reliability of the questionnaire was tested by calculating Cronbach's alpha coefficient (0.77). The mean scores and standard deviation of each gender were calculated and are presented under table1.

Table 1

Means and Standard Deviations of the Variables $(N=1324)$

\begin{tabular}{clll}
\hline Gender & $\mathrm{N}$ & Mean & SD \\
\hline Male & 485 & 3.68 & 0.51 \\
Female & 839 & 3.70 & 0.45 \\
\hline
\end{tabular}

Table 1 shows descriptive values of research variables of male and female. The total no of male participants was (485) and the mean value was 3.68 about their perception of assessment. Female participants were (839) and the mean was 3.70 about their perception of assessment. The mean of male participants' views regarding assessment (3.68) is a little bit less than the male participants' views regarding assessment (3.70) which shows that both genders have almost the same views about the assessment.

Table 2

Means and Standard Deviations of the Faculties

\begin{tabular}{llll}
\hline Faculties & $\mathrm{N}$ & Mean & SD \\
\hline FSS & 673 & 3.76 & 0.44 \\
FNS & 483 & 3.59 & 0.51 \\
FL & 168 & 3.73 & 0.45 \\
Total & 1324 & 3.69 & 0.47 \\
\hline NOTE: & FSS (Faculy & of Socil Scienc & (Faculty of
\end{tabular}

NOTE: FSS (Faculty of Social Sciences), FNS (Faculty of Natural Sciences), FL (Faculty of Languages)

Table 2 shows the descriptive statistics of three faculties (FSS, FNS, FL). Each faculty has a different number of participants as a maximum of 673 participants were of faculty of social sciences and minimum participants were 168 from faculty of languages while 483 participants were from faculty of natural sciences. The faculty of social sciences mean was highest (3.76) and the lowest mean was 3.59 as mentioned in the above table.

Table 3

Comparison of different faculties' participant's responses of Congruence with Planned Learning

\begin{tabular}{llllll}
\hline & Sum of squares & df & Mean square & F & Sig \\
\hline Between groups & 1.78 & 2 & 0.89 & 2.91 & 0.05 \\
Within groups & 403.58 & 1321 & 0.31 & & \\
Total & 405.36 & 1323 & & & \\
\hline
\end{tabular}


Table 3 shows the result of the sample t-test which is applied to compare the difference of different faculties' students' perception of assessment (the first-factor congruence with planned learning). The result presents that there was a significant difference $\mathrm{F}(2,1321)=2.91, p<.05)$ with students' perception of assessment of congruence with planned learning in all the three groups of faculties. It shows that all the three faculties of social sciences, natural, science, and languages have different perceptions of assessment. Students have different opinions about the congruence of planned learning.

Table 4

Comparison of different faculties' participant's responses to Authenticity

\begin{tabular}{llllll}
\hline & Sum of squares & df & Mean square & F & Sig \\
\hline Between groups & 27.56 & 2 & 13.78 & 24.78 & 0.00 \\
Within groups & 734.67 & 1321 & 0.55 & & \\
Total & 762.23 & 1323 & & &
\end{tabular}

Table 4 shows the result of the sample t-test which is applied to compare the difference of different faculties' students' perception of assessment (the second-factor authenticity). The result presents that there was a significant difference $\mathrm{F}(2,1321)=24.78, p<.000)$ with students' perception of assessment of authenticity in all three groups of faculties. It shows that all the three faculties of social sciences, natural, science, and languages have a different perception of assessment. Students have different opinions about authenticity.

Table 5

Comparison of different Faculties participants responses of Students' Consultation

\begin{tabular}{llllll}
\hline & Sum of squares & df & Mean square & F & Sig \\
\hline Between groups & 17.47 & 2 & 8.74 & 16.14 & 0.00 \\
Within groups & 715.22 & 1321 & 0.541 & & \\
Total & 732.69 & 1323 & & & \\
\hline
\end{tabular}

Table 5 shows the result of the sample t-test which is applied to compare the difference of different faculties' students' perception of assessment (the third-factor students' consultation). The result presents that there was a significant difference $\mathrm{F}(2,1321)=16.14, p<.000$ ) with students' perception of assessment of students' consultation in all the three groups of faculties. It shows that all the three faculties of social sciences, natural, science, and languages have a different perception of assessment. Students have a different opinion about the students' consultation in the assessment process.

Table 6

Comparison of Different Faculties Participants Responses of Transparency

\begin{tabular}{llllll}
\hline & Sum of squares & df & Mean square & F & Sig \\
\hline Between groups & 2.09 & 2 & 1.05 & 3.07 & 0.05 \\
Within groups & 448.88 & 1321 & 0.34 & & \\
Total & 450.97 & 1323 & & & \\
\hline
\end{tabular}

Table 6 shows the result of the sample t-test which is applied to compare the difference of different faculties' students' perception of assessment (the fourth-factor transparency). The result presents that there was a significant difference $\mathrm{F}(2,1321)=3.07, p<0.05)$ with students' perception of assessment of transparency in all three groups of faculties. It shows that all the three faculties of social sciences, natural, science, and languages have a different perception of assessment. Students have a different opinion about transparency in the assessment process.

Table 7

Comparison of Different Faculties Participants Responses of Students' Capabilities

\begin{tabular}{llllll}
\hline & Sum of squares & df & Mean square & F & Sig \\
\hline Between groups & 14.280 & 2 & 7.14 & 17.42 & 0.00 \\
Within groups & 541.50 & 1321 & 0.41 & & \\
Total & 555.78 & 1323 & & & \\
\hline
\end{tabular}

Table 7 shows the result of the sample t-test which is applied to compare the difference of different faculties' students' perception of assessment (the fifth-factor students' capabilities). The result presents that there was a significant difference $\mathrm{F}(2,1321)=17.42, p<0.00)$ with students' perception of assessment of students' capabilities in all the three groups of faculties. It shows that all the three faculties of social sciences, natural, science, and languages have a different perception of assessment. Students have a different opinion about the students' capabilities in the assessment process. 
Table 8

Effect of Faculty of Natural Sciences Participants' Views Regarding Assessment on Achievement

\begin{tabular}{llllll}
\hline Variables & $\mathrm{B}$ & SE & Beta & t & Sig \\
\hline Constant & 3.05 & 0.14 & & 22.34 & 0.00 \\
Congruence with planed learning & 0.01 & 0.01 & 0.10 & 1.83 & 0.06 \\
Authenticity & -0.01 & 0.01 & -0.12 & -2.17 & 0.03 \\
Students' consultation & -0.00 & 0.01 & -0.04 & -0.67 & 0.50 \\
Transparency & -0.00 & 0.01 & -0.01 & -0.17 & 0.86 \\
Students' capabilities & 0.02 & 0.01 & 0.17 & 3.06 & 0.00 \\
\hline
\end{tabular}

Table 8 presents the results of the regression coefficient which was used to find out the relationship of students' perception of assessment of the faculty of natural sciences on achievement. The results revealed that the two predictors (authenticity, $\mathrm{t}=2.17, \mathrm{p}<0.03$ and students' capabilities $\mathrm{t}=-3.06, \mathrm{p}<0.00$ ) of natural sciences participants' views regarding assessment have a significant relationship with the achievement. The remaining three predictors of Congruence with planned learning (0.10), Students' consultation, (-0.04), and transparency $(-0.01)$ were negatively correlated.

Table 9

Effect of Faculty of Social Sciences Participants' Views Regarding Assessment on Achievement

\begin{tabular}{llllll}
\hline Variables & $\mathrm{B}$ & $\mathrm{SE}$ & $\mathrm{Beta}$ & $\mathrm{t}$ & $\mathrm{Sig}$ \\
\hline Constant & 3.010 & 0.14 & & 21.38 & 0.00 \\
Congruence with planed learning & 0.00 & 0.01 & 0.03 & 0.60 & 0.55 \\
Authenticity & -0.01 & 0.01 & -0.05 & -1.24 & 0.22 \\
Students' consultation & -0.00 & 0.01 & -0.01 & -0.09 & 0.92 \\
Transparency & 0.01 & 0.01 & 0.09 & 1.92 & 0.05 \\
Students' capabilities & 0.00 & 0.01 & 0.02 & 0.42 & 0.67 \\
\hline
\end{tabular}

Table 9 presents the results of the regression coefficient which was used to find out the relationship of students' perception of assessment of the faculty of social sciences. The results revealed that the only one (transparency, $\mathrm{t}=1.921, \mathrm{p}<.055$ ) predictor of participants' views regarding assessment has a significant relationship with participants' achievement. The remaining four predictors of Congruence with planned learning (0.55), authenticity (0.22), Students' consultation, (0.92), and students' capabilities (0.67) were negatively correlated.

Table 10

Effect of Faculty of Language Participants' Views Regarding Assessment on Achievement

\begin{tabular}{llllll}
\hline Variables & B & SE & Beta & t & Sig \\
\hline Constant & 2.99 & 0.28 & & 10.64 & 0.00 \\
Congruence with planed learning & -0.01 & 0.01 & -0.06 & -0.79 & 0.43 \\
Authenticity & 0.01 & 0.01 & 0.08 & 0.96 & 0.34 \\
Students' consultation & 0.00 & 0.01 & 0.01 & 0.14 & 0.88 \\
Transparency & 0.03 & 0.01 & 0.32 & 4.02 & 0.00 \\
Students' capabilities & -0.03 & 0.01 & -0.24 & -2.95 & 0.00 \\
\hline
\end{tabular}

Table 10 presents the results of the regression coefficient which was used to find out the relationship of students' perception of assessment of the faculty of languages. The results revealed that the only two variables transparency $(\mathrm{t}=4.02, \mathrm{p}<0.00)$ and students' capabilities $(\mathrm{t}=-2.95, \mathrm{p}<0.00)$ were significant predictors in the regression model. The remaining three predictors of Congruence with planned learning (0.43), authenticity (0.35), and Students' consultation, $(0.88)$ were negatively correlated.

\section{Discussion}

This study identified the difference in students' perception among three faculties of public sector universities and their academic achievement. The results concluded that there were differences in the students' perception of the assessment process according to their faculty. It was also revealed that faculties have an impact on student's achievement levels. Sabbagh et al., (2020) mentioned that students could not be achieved good scores without the improvement of the institutions learning environment. Symth et al., (2016) concluded that examinees are affected by faculties and teaching methods of assessment. He explained that faculties indicate the students' learning methods that they adopt for high achievement.

Cheng et al., (2015) have studied the perception of students about assessment from the three selected universities and four major subjects as their study sample. He found a significant difference between students' perception of assessment and various subjects. Variables congruence with planned 
learning, students' consultation, and transparency have a significant difference. Cheng et al., (2015) suggested the teachers use some assessment practices in their daily instructions for the betterment of students. Assessment tasks should be related to the objectives of teaching and learning for the orientation of skills and improvement of students' abilities. The study findings (Galustyan, 2017) revealed that the difficulties and challenges of assessment should be resolved for the improvement of students' achievement levels in higher education. Different faculties used a variety of assessment methods according to the needs and requirements of learning material for the development of students' skills and creative abilities.

The study of Smyth et al., (2016) concluded that if the quality of teaching is improved on all the group of faculties, then the assessment system and students' achievement level will be increased automatically. Smyth et al.'s (2015) study findings revealed that the students, who are more concerned with the ir discipline and follow the pattern of study (deep study methods) of their senior students, achieved high scores. The achievement level of students is closely linked with the course material of their study fields and way of instruction (Lizzio et al., 2002; Platow et al. 2013).

The students from soft disciplines adopt deep study strategies and achieve high marks while the students from hard disciplines achieve low marks because of surface study strategies. The research study (Smyth et al., 2016) findings showed the significant difference between the soft and hard disciplines (pure disciplines and applied disciplines). They viewed prominent variations in students' achievements, perceptions, views, and experiences according to their faculties. These variations are caused by the different assessment methods and instructional methods (LindbolmYlänne et al., 2006). The current study results are in alliance with several research studies that there is variation in the perception of students regarding the assessment and students' achievement level is influenced by their faculty assessment pattern.

\section{Recommendations}

Based on study findings, it is recommended that students' perception of assessment should be considered for the betterment of students' achievement at the university level. Each faculty should well inform the students about the assessment methods and strategies for their outcome's improvement. As the participants of this study also opinioned that their teachers should avoid favoritism and improve their patience level and deliver clear instructions about the assessment process. With the help of this study findings, assessment stakeholders will be able to apply the appropriate assessment method according to the different faculties-based requirements.

\section{References}

Alawneh, M. (2016). Evaluating the academic performance of faculty members at Istiqlal University. International Specialized Journal, 5(3), 241-260.

Al-Otaibi, S. (2015). The training needs of faculty members in the light of effective teaching skills at the faculty of science, Princess Nourah bint Abdulrahman University. International Journal of Educational Specialization, 6(49), 140-160.

Batool, B. (2018). Perception of teacher Educators regarding the variety of assessments in ADE curricula. Institute of Education and Research (IER), UOB, Quetta Pakistan .5(1).

Cheng L., Wu, Y., \& Liu, X. (2015). Chinese university students' perceptions of assessment environment: Change et al. Language Testing in Asia, 5(13). DOI: 1o.11 86/ S 40468- 015-0020-6.

Coghill, D., \& Sonuga-Barke, E. J. (2012). Annual research review: categories versus dimensions in the classification and conceptualization of child and adolescent mental disorders-implications of recent empirical study. Journal of Child Psychology and Psychiatry,53(5),469-489. https://doi.org/10.1111/j.1469-7610.2011.02511.x.

Dkhikh, S., Hassanein, S., \&Masri, T. (2017). Methods of university teaching among faculty members of universities. Journal of Educational Sciences1 (3), 1-78.

Dweck, C. S. (2006). Mindset:The New Psychology of Success. Random House; 277

Elliott, E. S, Dweck, C. S. (1988). Goals: An approach to motivation and achievement. J PersSocPsychol, 54(1), 5-12.

Frankford, D. M., Patterson, M. A. \&Konrad, T. R. (2000). Transforming practice organizations to foster lifelong learning and commitment to medical professionalism. Acad Med,75 (7), 708-717.

Galustyan, O. V. (2017). Some methodological aspects of the evaluation of students 'educational achievements at university. International Journal of Cognitive Research in Science, Engineering and Education, 5(1), 43.

Howe A. (2002) Professional development in undergraduate medical curricula - the key to the door of a new culture?Med Educ, 36(4):353-359. https://doi.org/10.1046/j.1365-2923.2002.01168.x 
Klein, J., Delany, C., Fischer, M. D., Smallwood, D., \&Trumble, S. (2017). A growth mindset approach to preparing trainees for medical error.BMJ QualSaf, 26(9), 771-774.

Krathwohl, D. R. (2002). A Revision of Bloom's Taxonomy: An Overview. Theory into Practice, 41 (4), 212-218.

Krause, K. (2008). Blended learning strategy: Griffith University. Paper presented at the Inaugural ViceChancellor's Learning and Teaching Colloquium, 31 May, University of the Sunshine Coast, Queensland, Australia.

LaDonna, K. A., Hatala, R., Lingard, L., Voyer, S., \& Watling, C. (2017). Staging a performance: learners' perceptions about direct observation during residency. Med Educ, 51(5), 498-510.

Lenman, J., \&Shemmer, Y. (2012). Constructivism in practical philosophy.Oxford University Press.

Li, B., Shamsuddin, A. \& Braga, L. H. (2021). A guide to evaluating survey research methodology in pediatric urology.Journal of Pediatric Urology, 17 (2), 263-268. (https://www.sciencedirect. $\mathrm{com} / \mathrm{science} / \mathrm{article} / \mathrm{pii} / \mathrm{S} 1477513121000097)$

Lindbolm-Yla"nne, S., Trigwell, K., Nevgi, A., \&Ashwin, P. (2006). How approaches to teaching are affected by discipline and teaching context. Studies in Higher Education, 31(3), 285-298.

Lizzio, A., Wilson, K., \& Simons, R. (2002). University students' perceptions of the learning environment and academic outcomes: Implications for theory and practice. Studies in Higher Education, 27(1), 27-49. doi:10.1080/03075070120099359.

MacNeil, A. J., Prater, D. L., \& Busch, S. (2009). The effects of school culture and climate on student achievement.Int J Leadership Educ, 12(1), 73-84.

Mahasneh, O. (2020a). A proposed model for the university students' e-portfolio.Journal of Education and e-Learning Research, 7(1), 28-34.

Mahasneh, O. (2020b). The effect of teaching by (mobile learning) in university students' achievement. Paper presented at the Proceedings of the 16th International Conference Mobile Learning 2020, Bulgaria, IADIS.

Mahasneh, O. (2020c). Dataset on the perception among male secondary school students on underage smoking in Jordan. Paper presented at the Proceedings of the 16th International Conference Mobile Learning 2020, Data in Brief, 29.

Omar, M. K., Mohammad, N. M., Shima, M. S., Raed, A., \& Ali, S. (2020). Favorite Methods of Teaching and Evaluation among Students in University Colleges. International Journal of Education and Practice, 8(2), 365-378.

Platow, M. J., Mavor, K. I., \& Grace, D. M. (2013). On the role of discipline-related self-concept in deep and surface approaches to learning among university students.Instructional Science, 41(2), 271285. doi:10.1007/s11251-012-9227-4.

Sabbagh, H. J., Bakhaider, H. A., Abokhashabah, H.M. \& Bader, M. U. (2020). Students' perceptions of the educational environment: a cross-sectional study at King Abdulaziz University Faculty of Dentistry (KAUFD): a cross-sectional study. BMC Med Educ 20(241). https://doi.org/ 10.1186/s 12909-020-02165-7.

Smyth, L., Mavor, K. I., \&Platow, M. J. (2017). Learning behavior and learning outcomes: the roles for social influence and field of study. Social Psychology of Education, 20(1), 69-95.

Smyth, L., Mavor, K. I., Platow, M. J., Grace, D. M., \& Reynolds, K. J. (2015). Discipline social identific ation, study norms, and learning approach in university students. Educational Psychology, 35(1), 53-72. doi:10.1080/01443410.2013.822962.

Symth L., Mavor K. I., \&Platow M. J. (2016). Learning Behavior and Learning Outcomes: The Roles for Social Influence and Field of Study. SocPsycholEduc,35 (1), 53-72, DOI 10.1007/s 11218-0169365-7.

Tabernero, C. \& Wood, R. (19991). Implicit theories versus the social construal of ability in self-regulation and performance on a complex task. Organ Behav Hum Decis Process, 78(2), 104-127.

Tawarah, H., \&Mahasneh, O. (2020). The reality of university education in Jordan from the view point of faculty members. International Journal of Psychosocial Rehabilitation, 24(8), 7034-7037.

Teunissen, P. W., \& Bok, H. G. J. (2013). Believing is seeing: how people's beliefs influence goals, emotions, and behavior. Med Educ, 47(11), 1064-1072.

Thomas, L. (2020). An introduction to simple random sampling.https://www.scribbr.com/ methodology/simple-random-sampling/ 